\title{
An original technique for quantifying the flow-field characteristics in an electrodeposition process of $\mathrm{Zn}-\mathrm{SiO} 2$ with Fe
}

DOI:

10.1016/j.jallcom.2017.12.098

\section{Document Version}

Accepted author manuscript

Link to publication record in Manchester Research Explorer

Citation for published version (APA):

Xiao, Q., Pan, J., Fan, Y., Xu, J., \& Wang, H. (2018). An original technique for quantifying the flow-field characteristics in an electrodeposition process of $\mathrm{Zn}_{-} \mathrm{SiO}_{2}$ with $\mathrm{Fe}$. Journal of Alloys and Compounds, 737, 448455. https://doi.org/10.1016/j.jallcom.2017.12.098

\section{Published in:}

Journal of Alloys and Compounds

\section{Citing this paper}

Please note that where the full-text provided on Manchester Research Explorer is the Author Accepted Manuscript or Proof version this may differ from the final Published version. If citing, it is advised that you check and use the publisher's definitive version.

\section{General rights}

Copyright and moral rights for the publications made accessible in the Research Explorer are retained by the authors and/or other copyright owners and it is a condition of accessing publications that users recognise and abide by the legal requirements associated with these rights.

\section{Takedown policy}

If you believe that this document breaches copyright please refer to the University of Manchester's Takedown Procedures [http://man.ac.uk/04Y6Bo] or contact uml.scholarlycommunications@manchester.ac.uk providing relevant details, so we can investigate your claim.

\section{OPEN ACCESS}




\title{
An original technique for quantifying the flow-field characteristics in an electrodeposition process of $\mathrm{Zn}-\mathrm{SiO}_{2}$ with $\mathrm{Fe}$
}

\author{
Qingtai Xiao ${ }^{a, b}$, Jianxin $\operatorname{Pan}^{c}$, Yunying Fan ${ }^{d}$, Jianxin Xu ${ }^{a, c, e, *}$, Hua Wang ${ }^{a, b, *}$ \\ ${ }^{a}$ State Key Laboratory of Complex Nonferrous Metal Resources Clean Utilization, Kunming University of Science and \\ Technology, Kunming 650093, PR China \\ ${ }^{b}$ Faulty of Metallurgical and Energy Engineering, Kunming University of Science and Technology, Kunming 650093, PR \\ China \\ ${ }^{c}$ School of Mathematics, The University of Manchester, Manchester M13 9PL, UK \\ ${ }^{d}$ School of Material Science and Engineering, Kunming University of Science and Technology, Kunming 650093, PR China \\ ${ }^{e}$ Quality Development Institute, Kunming University of Science and Technology, Kunming 650093, PR China
}

\begin{abstract}
The purposed of this article is to introduce a novel approach (uniformity measure, $U$ ) based on entropy theory for measuring the micron-particle blend homogeneity of aqueous electrolytes, which applies directly to the imaging data of flow field and does not require contacting and disturbing it. Effectiveness of the new method has been illustrated on synthetic imaging data. To verify the feasibility of our method for real experimental data, we analyze the flow-field images from electrodeposited $\mathrm{Zn}-\mathrm{Fe}-\mathrm{SiO}_{2}$ composite coatings process. The numerical results showed that the potential of proposed method was demonstrated successfully to quantitatively establishes association between plating parameters and flow field characteristics. The possible recommendations are to monitor the deposition of micro-particles during the composite electrodeposition processes and to apply this technique for studying a variety of multiphase mixing problems in which assessment of uniformity is required.
\end{abstract}

Keywords: flow-field characteristics; composite electrodeposition; uniformity measure; plating parameters;

$\mathrm{Zn}-\mathrm{Fe}-\mathrm{SiO}_{2}$.

${ }^{*}$ Corresponding authors at: State Key Laboratory of Complex Nonferrous Metal Resources Clean Utilization, Kunming University of Science and Technology, Kunming 650093, PR China (J. Xu, H. Wang). Tel./Fax.: +86-0871-65157341. E-mail addresses: qingtaixiao2016@kmust.edu.cn (Q. Xiao); jianxin.pan@manchester.ac.uk (J. Pan); yunyingfan7739@sina.com (Y. Fan); jianxin.xu@manchester.ac.uk, xujianxina@163.com (J. Xu); wanghua65@163.com (H. Wang). 


\section{Introduction}

As one of the most significant metallic material surface finishing technologies and metal-based composite material preparation technologies, composite electrodeposition plating technology is widely adopted to prepare the new chemical materials with satisfactory performance 1, 2, 3, 4. In particular, it 5 is one of most commonly practiced industrial techniques for the fabrication of zinc coatings which are widely used for the corrosion protection of ferrous materials, acting both as a physical barrier from the surrounding corrosive environment and as a self-sacrificial anodic protective layer [5, 6, 7, 8, There are two basic types of Zn and Zn alloy plating baths currently available: acid and alkaline type 9, 10, 11. Blend homogeneity is key to composite electrodeposition, and researchers put substantial resources into inspiring flow field to develop mixing uniformity. Zinc is a well-known sacrificial coating material for iron and co-deposition of suitable particles is of interest for further improving its corrosion protection performance 12, 13, 14. Electrodeposition of zinc-iron alloys is of practical importance since they have better corrosion resistance and mechanical properties than pure zinc coating [15, 16]. Although some of the open research focused on electroplating technological parameters and electrochemical theory, the number of publications which address the quantification of flow-field characteristics of electrolyte solution is very limited 17.

Studies show that the mixing quality of electrolyte solution and the electrochemical reaction on the surface of are important for appraising performance of composite electrodeposition. However, the reports have not been completely able to provide a quantitative interpretation of mixture. Khan et al. (2011) reported a detailed study of $\mathrm{Zn}-\mathrm{SiO}_{2}$ nanocomposite coatings deposited from a zinc sulfate $\left(\mathrm{ZnSO}_{4}\right)$ solution 20 at $\mathrm{pH}=3$ [13. Shahri et al. (2013) prepared a new nanocomposite coatings by means of the conventional electrodeposition in chloride solution containing different concentrations of hexagonal boron nitride particles 18. Xia et al. (2013) investigated the microstructure of Ni-AlN composite coatings prepared by pulse electrodeposition technology [19].

Although material or fluid images contain a huge array of data about the identity, position, intensity 25 and distribution of chemical species on a surface, processing these images to obtain concise electrochemical information can be a formidable challenge $20,21,22$. Image processing technique with advanced statistical 
methods or other mathematical theories is gaining in importance for feature extraction [23, 24, 25, 26]. Zaborowski et al. (1995) developed a method for quick comparison of the quality of an Al surface by digital image processing [27]. Lapsker et al. (1996) used two topological analysis, including fractal dimensionality and 2D-Fourier spectral analyses, for classifying the surface morphology in the various zones of the laser beam written thin film [28]. Coënt et al. (2005) showed an original image-processing technique for obtaining the mixing time: The box-counting with erosions method. Oshida et al. (2013) observed the space structure of the nanotubes by 3D-TEM and revealed the detailed structure by HRTEM, which is useful to understand the nano-structure of materials accurately [29]. Recently, we showed an image analysis technique combined with two statistical hypothesis-testing tools including Kolmogorov-Smirnov test and $\chi^{2}$ test to obtain the $p$-values for bubble images comparison [30].

Analysis of images from flow field have been made so far, although they are limited to qualitative or semiquantitative analyses. The information in such an image is very useful in terms of position and intensity. Positions of images show the structure of the material. In order to learn about the accuracy of images, 40 quantitative analysis of images is necessary. From the foregoing it is seen that the technique presented in this current article represents an extension of our tools in the field of the mixing characterization of electroplating bath composition. This study mainly focuses on the blend homogeneity of electrodeposition flow field.

The contributions of this work are two-fold. First, from flow field analysis point of view, our proposal timely responds to a number of growing needs of quantitative characterization of subjective human experience. Second, from a composite electrodeposition point of view, our proposal develops a general framework for understanding association between plating parameters and flow field characteristics. Furthermore, using the mixing uniformity coefficient as the observable, one can take recordings for a interval of time. The 0-1 test method [31, 32] and three state test (3ST) 33, 34] could be employed for chaos detection of the flow field once the time series data can be obtained.

The rest outline of the article is organized as follows. In the next section, the experimental setup and the scheme of the proposed methodology are presented. Then the results and discussion are shown in Section 3 
while the conclusions are briefly summarized in Section 4 finally.

\section{Experiments and methodology}
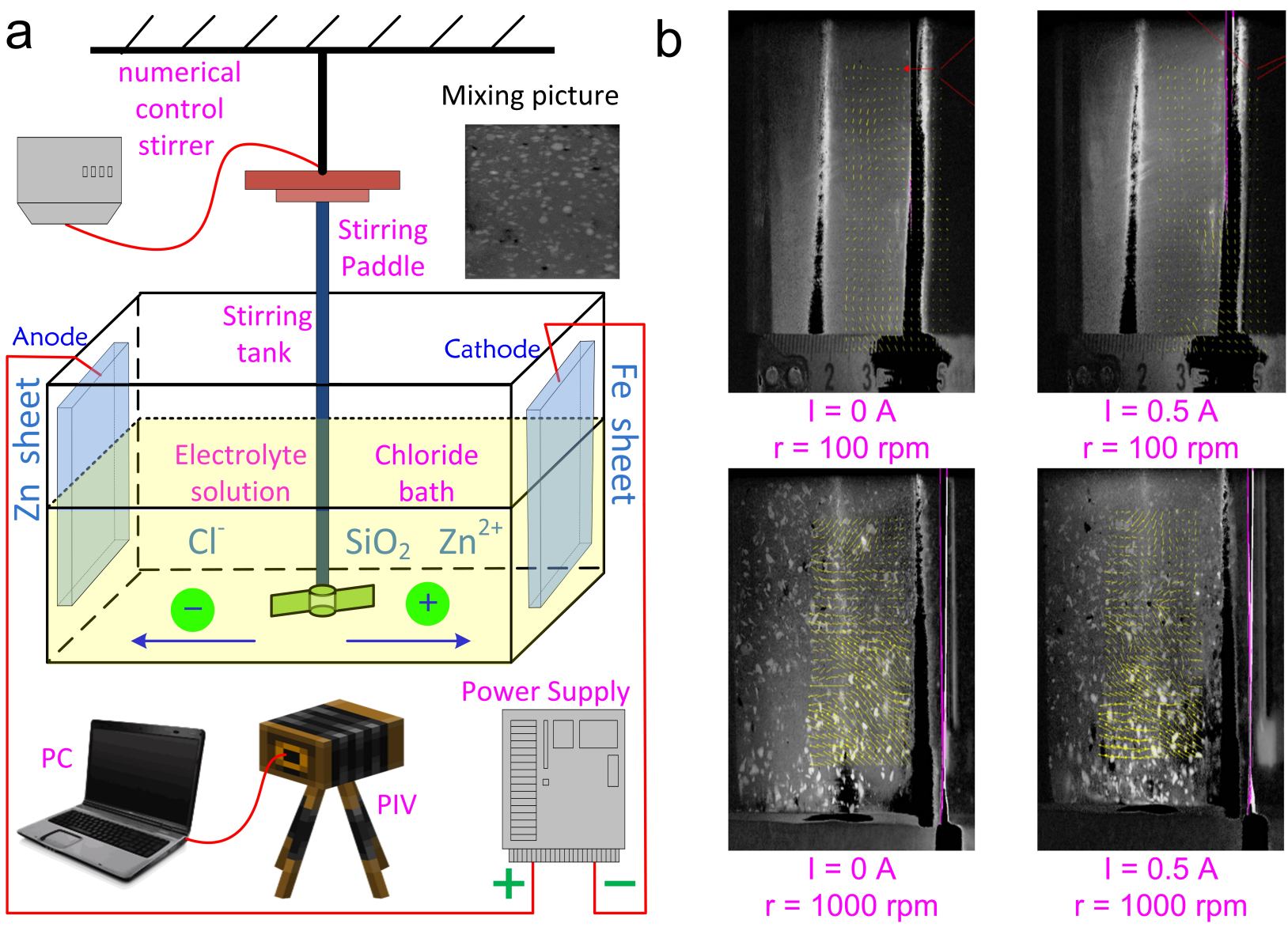

Figure 1: Schematic diagram of experimental electrodeposition apparatus (a: the bath composition consists of chloride and $\mathrm{SiO}_{2}$ particles; the $\mathrm{Zn}$ sheet represents the anode whereas the Fe sheet represents the cathode; a mixing picture corresponding to the mixed state of electrolyte solution at $s=1 \mathrm{~cm}, I=0.5 \mathrm{~A}, r=1000 \mathrm{rpm}$ and $h=10 \mathrm{~mm}$ ) and PIV images reported by Ref. 35. (b: considering different $I$ and $r$ at $h=10 \mathrm{~mm}$ ).

In this present research, the procedure of zinc-silica $\left(\mathrm{Zn}-\mathrm{SiO}_{2}\right)$ composite plating consists of: (a) foretreatment of matrix; (b) plating; (c) rinsing; (d) dry. The schematic diagram of the acquisition system and the reactor is shown in Fig. 1. The length $L$, width $W$, and height $H$ of the cubic reactor were $150 \mathrm{~mm}$, $100 \mathrm{~mm}$ and $120 \mathrm{~mm}$, respectively. Electrodeposition experiments were performed at room temperature 
$\left(25^{\circ} \mathrm{C} \pm 2^{\circ} \mathrm{C}\right)$ using zinc chlorate-based electrolytes, containing $\mathrm{ZnCl}_{2}$ (80 g/L, as base fluid), $\mathrm{KCl}(220 \mathrm{~g} / \mathrm{L})$, $\mathrm{H}_{3} \mathrm{BO}_{3}(25 \mathrm{~g} / \mathrm{L})$, brightening agent $(0.5 \mathrm{~g} / \mathrm{L})$ and $\mathrm{SiO}_{2}$ particles $(1 \mathrm{~g} / \mathrm{L}$, average particle size is $11.07 \mu \mathrm{m})$ and its $\mathrm{pH}$ value was 5.5. More specifically, the materials used for our electrodeposition experiments were chemical analytic pure, which were all purchased from Tianjin Fuchen Chemicals Reagent Factory (Hebei, China). The viscosity and density of the electrolyte solution were regulated using the viscosimeter and the weighing method, respectively. The solution conductivity and surface tension were measured using the conductivity meter and surface tension tester, respectively. The stirring rate of the electric stirrer and the electric current of the electrodeposition device are kept in the range of $0 \sim 3000 \mathrm{rpm}$ and $0 \sim 0.5$ A, respectively. The size of stirring paddle was $2 \mathrm{~mm} \times 10 \mathrm{~mm} \times 6 \mathrm{~mm}$, whereas the height of paddle was 10 30 mm. The cathode was an iron plate and the anode was a zinc plate. In this work, the physical characteristic parameters were also obtained. For instance, the density of electrolyte $\left(1.16 \sim 1.18 \mathrm{~g} / \mathrm{cm}^{3}\right)$ was determined by the weighting method; solution conductivity $(0.75 \sim 0.95 \mu \mathrm{s} / \mathrm{cm})$ was measured by a conductivity meter; surface tension $(40.5 \sim 41.0 \mathrm{mN} / \mathrm{m})$ was determined by a surface tension tester; the dynamic viscosity $\left(1.50 \sim 1.52 \times 10^{-3} \mathrm{~Pa} \cdot \mathrm{s}\right)$ and kinetic viscosity $\left(1.51 \sim 1.53 \times 10^{-6} \mathrm{~m}^{2} / \mathrm{s}\right)$ were measured by a viscometer and the size of $\mathrm{SiO}_{2}$ particles (around $10 \mu \mathrm{m}$ ) were determined by a laser particle size analyzer. and design parameters with different levels are present in Ref. [36, 35]. As listed in above references, four different parameter, including the distance between the cross section tested by PIV and cathode $s$ (unit: $\mathrm{cm}$ ), stirring rate $v$ (unit: rpm), electric current $I$ (unit: A) and the height of paddle $h$ (unit: $\mathrm{cm}$ ), were used to investigate the blend homogeneity in the $\mathrm{Zn}-\mathrm{Fe}-\mathrm{SiO}_{2}$ electrodeposition process. The operating parameters of the vessels used in this work are summarized in Table 1

Table 1: List of experimental conditions investigated with PIV in electrodeposition rector.

\begin{tabular}{cccccc}
\hline \multirow{2}{*}{ Description } & \multirow{2}{*}{ Parameter } & \multicolumn{4}{c}{ Level } \\
\cline { 3 - 5 } & & 1 & 2 & 3 & Unit \\
\hline Current & $I$ & 0 & 0.25 & 0.5 & $\mathrm{~A}$ \\
Distance & $s$ & 1 & 3 & 5 & $\mathrm{~cm}$ \\
Height & $h$ & 10 & 20 & 30 & $\mathrm{~mm}$ \\
Velocity & $r$ & $1 \times 10^{3}$ & $2 \times 10^{3}$ & $3 \times 10^{3}$ & $\mathrm{rpm}$ \\
\hline
\end{tabular}


Table 2: Design experiments of experimental cases according to previous work.

\begin{tabular}{cccccc}
\hline Cases & $I(\mathrm{~A})$ & $s(\mathrm{~cm})$ & $h(\mathrm{~mm})$ & $r(\mathrm{rpm})$ & $t(\mathrm{~s})$ \\
\hline $\mathrm{C}_{1}$ & 0.5 & 5 & 10 & $3 \times 10^{3}$ & 10 \\
$\mathrm{C}_{2}$ & 0.25 & 5 & 20 & $2 \times 10^{3}$ & 20 \\
$\mathrm{C}_{3}$ & 0 & 5 & 30 & $1 \times 10^{3}$ & 10 \\
$\mathrm{C}_{4}$ & 0.25 & 3 & 30 & $3 \times 10^{3}$ & 20 \\
$\mathrm{C}_{5}$ & 0 & 3 & 10 & $2 \times 10^{3}$ & 10 \\
$\mathrm{C}_{6}$ & 0.5 & 3 & 20 & $1 \times 10^{3}$ & 20 \\
$\mathrm{C}_{7}$ & 0 & 1 & 20 & $3 \times 10^{3}$ & 10 \\
$\mathrm{C}_{8}$ & 0.5 & 1 & 30 & $2 \times 10^{3}$ & 20 \\
$\mathrm{C}_{9}$ & 0.25 & 1 & 10 & $1 \times 10^{3}$ & 10 \\
$\mathrm{C}_{10}$ & 0 & 1 & 10 & $2 \times 10^{3}$ & 20 \\
$\mathrm{C}_{11}$ & 0.25 & 1 & 10 & $2 \times 10^{3}$ & 10 \\
$\mathrm{C}_{12}$ & 0.5 & 1 & 10 & $2 \times 10^{3}$ & 20 \\
$\mathrm{C}_{13}$ & 0 & 1 & 10 & 0 & 10 \\
$\mathrm{C}_{14}$ & 0.25 & 1 & 10 & 0 & 10 \\
$\mathrm{C}_{15}$ & 0.5 & 1 & 10 & 0 & 10 \\
\hline
\end{tabular}

In the previous work, Ref. 3] recorded the actual flow state by Particle Image Velocimetry (PIV), as well as finishing the numerical simulation of flow field of $\mathrm{Zn}-\mathrm{SiO}_{2}$ composite electrolyte by FLUENT software. It is worth to remark that 15 samples selected from the experiment cases were recoded repeatedly $(10 \mathrm{~s}, 20$ $\mathrm{s}$ or $30 \mathrm{~s}$ ) in order to investigate the blend homogeneity of electrolyte solution. In this current work, the symbols and numbers $\mathrm{C}_{1}-\mathrm{C}_{15}$ denote different experimental levels, as shown in Table. 2

\subsection{Mixing images acquisition}

PIV test is one of the highest resolution analysis methods for investigating flow-field characteristics. The obtained mixing images were recorded on high-speed video camera (PRAKTICA from Germany) whose dynamic intensity range is from $10^{3}$ to $10^{4}$, which is enough for the present investigation. A typical image of the vessel obtained by the above described apparatus is shown in Fig. 17. Digital image processing technology was employed to deal with the real-time images of mixing particles in the flow field of electrodepostion experiment into the computing objective below. Subsequently, the picture was quantitatively measure with a resolution of $1200 \times 1200$. The digitalized intensity was processed by personal computer $(\mathrm{PC})$ and displayed in various forms. 


\subsection{Proposed method}

The proposed measure of uniformity is based on a novel core idea in terms of that how to define uniformity of an image. Generally speaking, the image rapidly collected and stored by currently available instrumentation contains the full mass spectrum at every image pixel. Like hypothesis testing in statistics, assuming an $\alpha$ smaller than the instantiated $p$-value will end up not rejecting the null hypothesis. Hence, the content of information was inversely associated with probability $P$ of the events and the novel core idea is that if the image has many regular blend, the image uniformity will be more worse (see Fig. 2, a counterexample). The description of the original technique follows in detail.
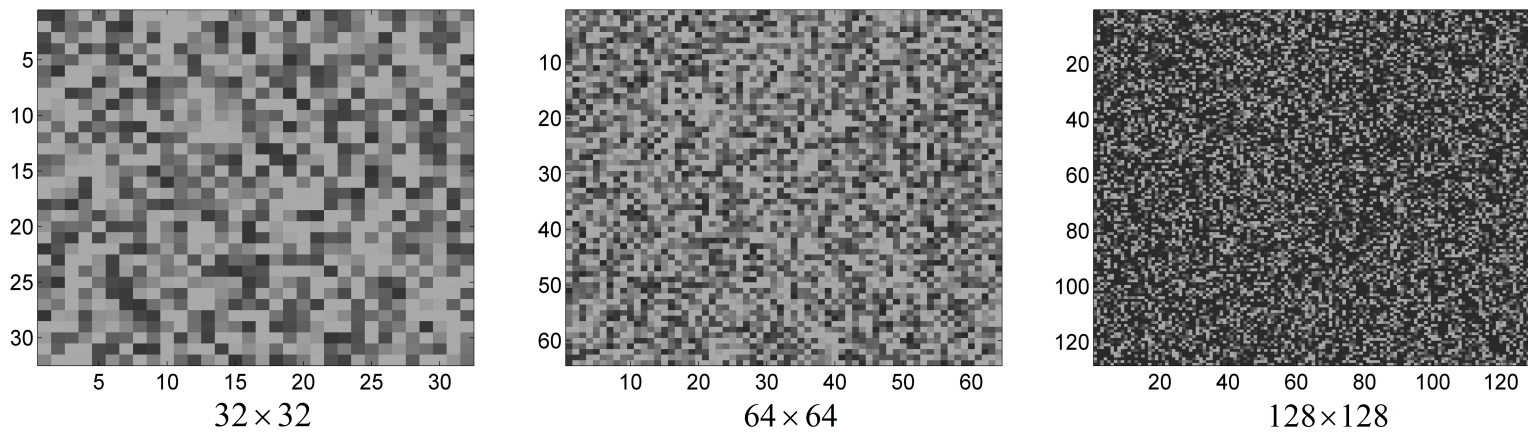

Figure 2: Illustration of three most uniform synthetic images (corresponding to $U=1$ ) of mixing system obtained by three computer experiments (left: $32 \times 32$; middle: $64 \times 64$; right: $128 \times 128$ )

Definition 1. Generally, for two unrelated events, it is expected that the occurrence of one does not affect the information content of occurrence of other. In order to define a function $f_{0}$ for information content of a point set, the logarithmic function $\log$ of $P$ is therefore given by:

$$
f_{0}(P)=-\log _{a}(P)
$$

Definition 2. In particular, for an gray-scale intensity image its image entropy indicated by $f_{1}$ is given by:

$$
f_{1}=E\left(f\left(P_{c}\right)\right)=\sum_{i=0}^{255} P\left(c_{i}\right) f\left(P\left(c_{i}\right)\right) \triangleq-\sum_{i=0}^{255} P_{i} \log _{256}\left(P_{i}\right)
$$

where $c_{i}$ represents the $i$ th gray-scale intensity from 0 to 255 and $P\left(c_{i}\right)$ represents the probability of 
occurrence of $c_{i}$. However, not all gray-scale intensity between 0 and 255 exist in a digital image for some real-world applications, as shown in Fig. 3a.
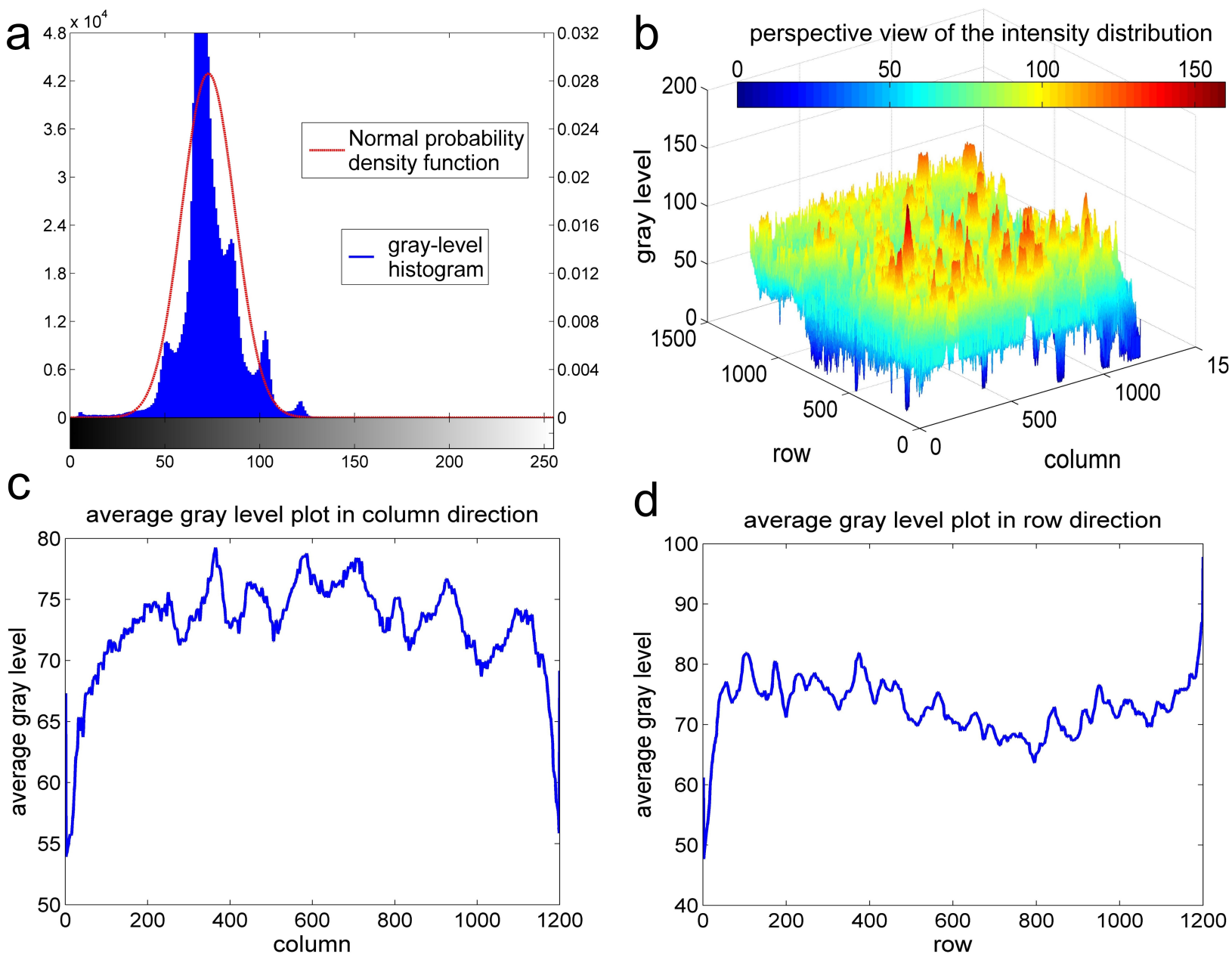

Figure 3: The statistical image analysis (a: gray-level histogram and Normal probability density function, b: perspective view of intensity distribution) and the average gray level (c: in the column direction; d: in the row direction) of a gray-scale image at the top-right corner of Fig. 1 corresponding to the mixed electrolyte solution.

Definition 3. Inspired and motivated by previous section, we introduce an alternative approach, modified image entropy method for this situation to improve the uniformity metric. Let

$$
B=\left(b_{1}, b_{2}, b_{3}, \cdots, b_{m}\right) \in \Delta_{m},
$$


where

$$
\Delta_{m}=\left\{\left(b_{1}, b_{2}, \cdots, b_{j}, \cdots, b_{m}\right) \mid b_{j} \geq 0, m \geq 2, \sum_{j=1}^{m} b_{j}=1\right\}
$$

is a set of discrete finite $m$-ary probability distributions. The modified image entropy indicated by $g$ is given by:

$$
g=E\left[f\left(P_{b}\right)\right]=\sum_{j=1}^{m} P\left(b_{j}\right) f\left(P\left(b_{j}\right)\right)=-\sum_{j=1}^{m} P_{j} \log _{m}\left(P_{j}\right)
$$

where $b_{j}$ denotes the $j$ th gray-scale intensity existed in the set of positive integers $\{0,1,2, \cdots, 255\}$. In particular, the most uniform cases occurs when all (corresponding to $g=1, P\left(b_{1}\right)=P\left(b_{2}\right)=P\left(b_{m}\right)=\cdots=$ $\frac{1}{m}$ ), whereas the most non-uniform case occurs when all the pixels are at the same level (corresponding to $g=0)$.

Definition 4. According to the previous analyses, our uniformity measure function indicated by $U$ must focus on that $U$ should increase but not outnumber 1 as the uniformity of mixture distribution improves. Moreover, the uniformity measure should also be dependent on the position of pixels. So the homogeneity index of the local mixing system based on direct imaging technology is shown as below:

$$
U=1-\frac{1}{K-1} \sqrt{\sum_{k=1}^{K}\left(g_{k}-\bar{g}\right)^{2}}
$$

\section{Results and discussion}

In this section, experimental results of applying the proposed method to the experimental images along with the statistical analyses and comparison with other existing method are reported. The following 
calculations are all performed by using MATLAB R2014a on a PC with Intel(R) Core(TM) i5-6300HQ 2.30 GHZ processor. For qualitative and quantitative analysis of performance of the proposed method an gray-scale photograph and some FLUENT images are considered. The dimension of all the images are $1200 \times 1200$.

\subsection{Transient analysis of the mixing patterns}

Statistical image analysis was employed to study the mass transfer. In the top-right corner of Fig. 11a, a mixing pattern which is a real example of mixed region was shown at a given moment in the electrodeposition experiment. It can be seen that the highly intense regions in this observation are saturated. As shown in Fig. 3 a, a bell shaped distribution of the mixing pattern was obtained. However, this is made to show weak $\mathrm{SiO}_{2}$ particles clearly and the real picture does not saturate. In order to improve this, a perspective view of the intensity distribution is given in Fig. 3b corresponding to the above image. Fig. 3r shows the average gray level in the column direction while Fig. $3 \mathrm{~d}$ shows the average gray level in the row direction. We found that the average gray level increases at one end and increases or decreases at the other end, while they become stabilised on the central regions due to the homogeneity of the mixture. Therefore, we get a qualitative and semi-quantitative evaluation result that is in line with subjective perceptive quality.

From Fig. 4, we obtained $U=0.9507$ which is closer to 1 . It is indicated that this mixing transient is homogeneous. On the other hand, we investigated the core equation (5) in detail in this part of the study. We applied the uniformity measure $U$ with different input parameter $m$ to the mixing picture obtained by our camera. Fig. 4 also represents the effect of varying the current base number of input parameter on the homogeneity evaluation of mixing picture. By increasing the base number from 1 to 256 , the $U$ rose as a whole. It can be noticed that the higher the base number, the higher the value of $U$ before $m=161$. For $m=256, f_{1}$ is smaller than $U$. According to above data and curves, the base number has an important influence on uniformity measure. It is important to select a very suitable parameter to understand the uniformity ranking and the influence degree of operating parameters on the mixing effect of electrolyte solution. Meanwhile, we believe that the high value of $U$ is associated with the fluid flow between the various compounds. Indeed, the mixing can be considered as completely homogeneous when the uniformity 


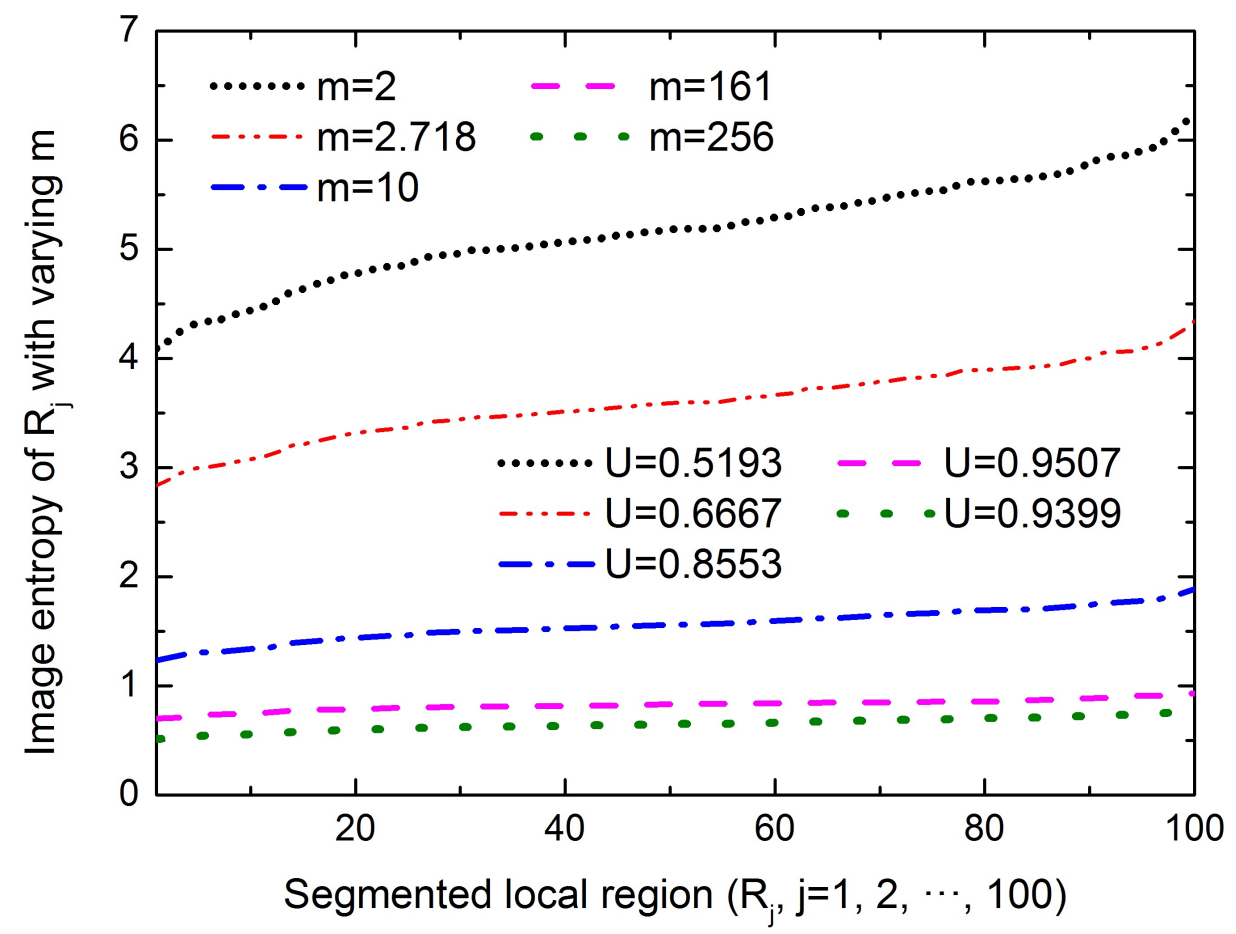

Figure 4: Effect of the common base number (namely, $m$ in Eq. 5) on modified image entropy and uniformity measure (namely, $U$ in Eq. 6) for the real CCD picture of electrolyte solution in Fig. 17a. (For interpretation of the references to color in this figure legend, the reader is referred to the web version of this article.)

measure $U$ reaches a value which nearly equal to 1 (about 0.9 ).

\subsection{Experimental verification of the measure}

To investigate the effect of flow-field characteristics of electrolyte solution on electrodeposited zinc-silica composite plating, the PIV system was used to record and test the actual flow field of zinc-silica composite electrolyte, as shown in Fig. $5 \mathrm{a}$ and Fig. $5 \mathrm{p}$ which corresponds the experimental cases of $\mathrm{C}_{9}(I=0.25 \mathrm{~A}$, $s=1 \mathrm{~cm}, h=10 \mathrm{~mm}, r=1000 \mathrm{rpm})$ and $\mathrm{C}_{11}(I=0.25 \mathrm{~A}, s=1 \mathrm{~cm}, h=10 \mathrm{~mm}, r=2000 \mathrm{rpm})$ at $t=10 \mathrm{~s}$, respectively. However, it actually provided incomplete pictures in nearly all the experiments because a few portion of particles were not captured by the video camera. According to Ref. [3], the numerical simulation of flow-field of zinc-silica composite electrolyte has been finished by FLUENT software (for example, Fig. 5. and Fig. 5d which corresponds to the same experimental conditions as Fig. 5 a and Fig. 5b, respectively.). Fan et al. also reported that the simulation results of flow field was approximately similar to the actual flow state and the contrast results proved the reliability of numerical simulation. To test the validity of 
this technique, therefore, those simulation images could be employed for measuring mixing uniformity of electrolyte solution instead of PIV images and had the uniformity measure calculation results with $U=0.8743$ and $U=0.7430$, respectively. It is obviously that the former case exhibits better mixing uniformity than the other one.

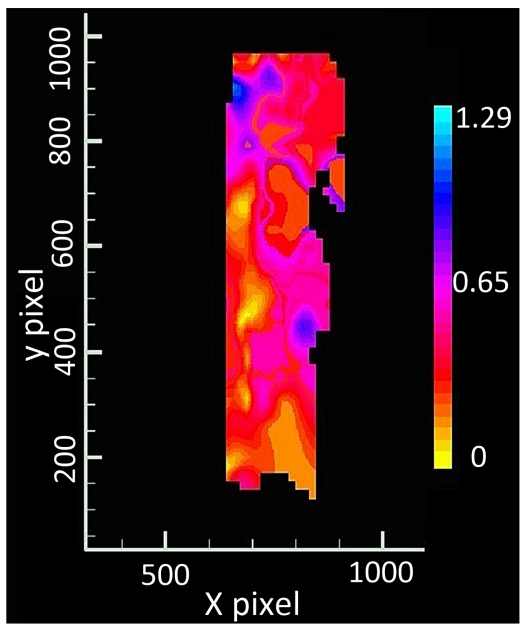

a. PIV image from $\mathrm{C}_{9}$

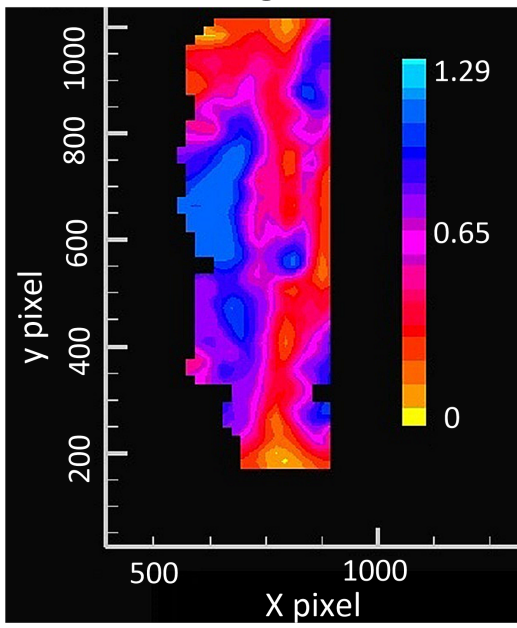

b. PIV image from $\mathrm{C}_{11}$

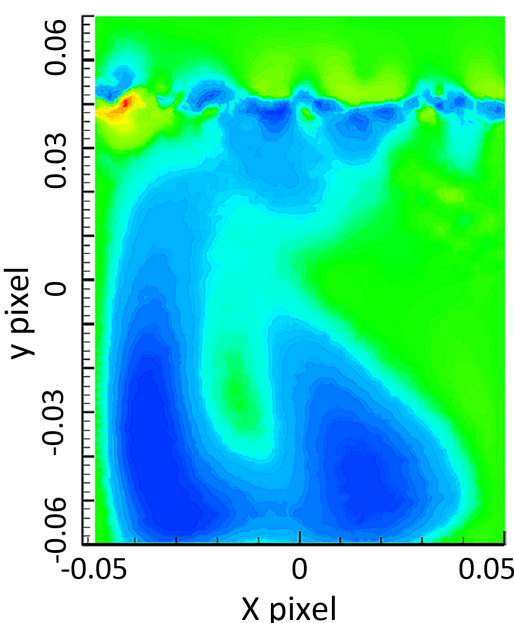

c. FLUENT image from $\mathrm{C}_{9}$

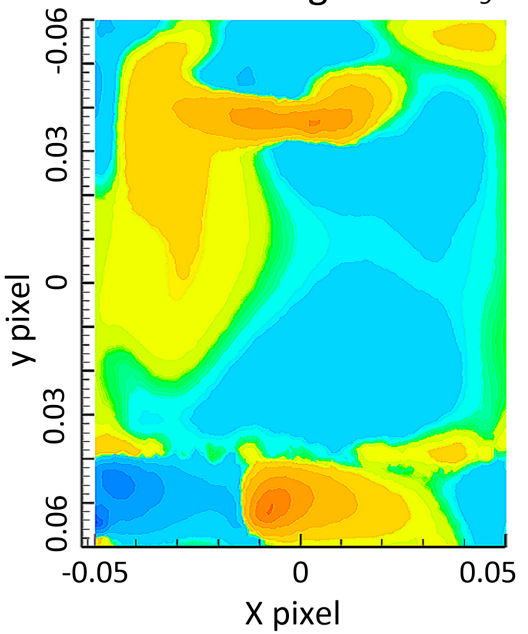

d. FLUENT image from $C_{11}$
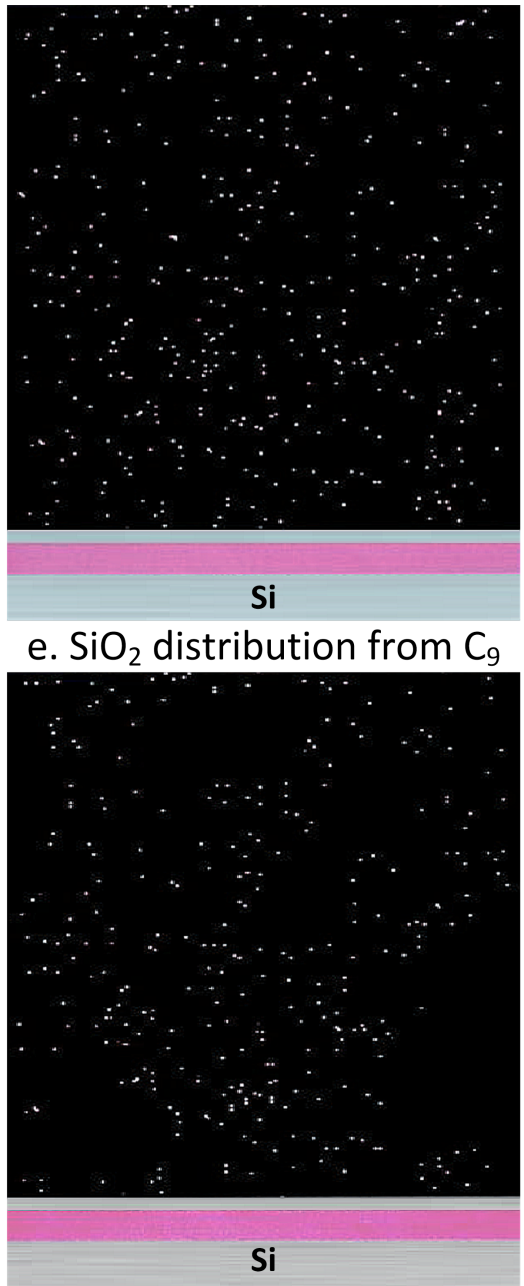

f. $\mathrm{SiO}_{2}$ distribution from $\mathrm{C}_{11}$

Figure 5: Real images recorded by PIV system (a and b), simulation images obtained by FLUENT software (c and d) and $\mathrm{SiO}_{2}$ content distribution tested by an electron probe (e and f) from two experimental cases $\mathrm{C}_{9}$ and $\mathrm{C}_{11}$. (For interpretation of the references to color in this figure legend, the reader is referred to the web version of this article.) measurements have been conducted with the assistance of electron probe testing, a magnetic thickness tester, and an erosion test 37, 35. Closer inspection on Fig. 5e and Fig. 5F, it is noticed that $\mathrm{SiO}_{2}$ is well 
distributed in the first cases, and there is clearly some empty area in the second one which proves that the flow field mixing is not so balanced. This qualitative judgment was quantitatively demonstrated according to this current work. In addition, Table 3 presents three performance parameters, including silica content in composite coatings, thickness of coatings and red rust time in Neutral Salt Spray (NSS) time, of composite coatings in 9 sites of plated steel sheet for two different experimental cases $\mathrm{C}_{9}$ and $\mathrm{C}_{11}$. It can be seen that $\mathrm{C}_{9}$ outperforms $\mathrm{C}_{11}$ at all the sites from the standard deviation (SD) average analysis point of view.

Table 3: Three performance parameters of composite coatings in 9 sites of plated steel sheet for two different experimental cases.

\begin{tabular}{ccccccc}
\hline \multirow{2}{*}{ Sites } & \multicolumn{2}{c}{$\mathrm{SiO}_{2}$ content in } & \multicolumn{2}{c}{ Thickness of } \\
& \multicolumn{2}{c}{ composite coatings $[\%]$} & \multicolumn{2}{c}{$\begin{array}{c}\text { Red rust time in } \\
\text { coatings }[\mu \mathrm{m}]\end{array}$} & \multicolumn{2}{c}{ NSS test $[\mathrm{h}]$} \\
\cline { 2 - 7 } & $\mathrm{C}_{9}$ & $\mathrm{C}_{11}$ & $\mathrm{C}_{9}$ & $\mathrm{C}_{11}$ & $\mathrm{C}_{9}$ & $\mathrm{C}_{11}$ \\
\hline 1 & 0.48 & 0.63 & 22.00 & 23.40 & 440 & 409 \\
2 & 0.50 & 0.51 & 20.90 & 21.30 & 424 & 409 \\
3 & 0.50 & 0.36 & 22.25 & 18.65 & 440 & 389 \\
4 & 0.51 & 0.61 & 21.50 & 22.40 & 424 & 424 \\
5 & 0.52 & 0.54 & 20.65 & 21.65 & 416 & 432 \\
6 & 0.52 & 0.38 & 21.70 & 19.50 & 424 & 393 \\
7 & 0.54 & 0.44 & 21.95 & 20.40 & 440 & 401 \\
8 & 0.56 & 0.51 & 21.65 & 21.20 & 424 & 417 \\
9 & 0.55 & 0.60 & 22.30 & 23.70 & 448 & 424 \\
SD & 0.05 & 0.08 & 0.25 & 1.56 & 11.31 & 5.66 \\
Average & 0.52 & 0.51 & 21.66 & 21.36 & 431 & 411 \\
\hline
\end{tabular}

\subsection{Uniformity ranking of mixing transient}

As above section, the image databases photographed by PIV in this work could not be complete due to

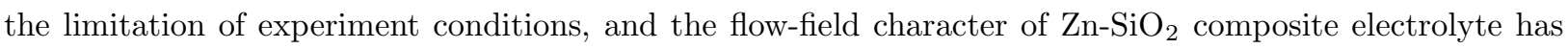
been investigated by computer simulations $[3$. Performance comparison between the novel technique and the existing method was therefore carried out by means of the data from the numerical simulation experiments in this current part. Based on the results obtained from the previous work, performance comparison in the application of numerical simulation results ranking will be limited to the traditional fractal dimension $D[38$, maximum relative velocity $v_{\max }$ and the proposed uniformity measure $U$. Specifically, this section presents the new engineering application of uniformity measure in the field of numerical simulation. The proposed measure is an original method of characterizing dynamic behaviors of electrolyte under the different stirring 
conditions. From Fig. 6a, the comparison of $U$ with $v_{\max }$ can be seen for 15 experimental cases while Fig. 6p

shows the comparison of $U$ and $D$.

According to this figure, it is obvious that the zig-zag patterns of the three curves are very close and the differences in them are evident in case of some individuals. The difference in patterns of zig-zag can be interpreted as follows: theoretically speaking, the quality of mixing state and the relative velocity of flow field tend towards congruency and the changes in maximum relative velocity shows the variations in mixing state of the flow field; fractal dimension $D$, the measure of complexity and the proposed mixing index $U$, the measure of uniformity can be used to characterize the quality of mixing state of the flow field; $U$ and $D$ have a significant and relatively high sensitivity because the concept of fractal dimension can also be used to quantify the deviation from the uniformity distribution. However, the precise definition of fractal dimension is actually very difficult to determine because the calculations of different fractal dimensions are commonly based on different application backgrounds. Closer inspection shows that the proposed uniformity measure $U$ is capable of ranking the simulation images in an order that is agreeable to the $v_{\max }$ and $D$ for experiments $\mathrm{C}_{1}-\mathrm{C}_{7}$ and $\mathrm{C}_{13}-\mathrm{C}_{15}$. Those demonstrated that the relationship between mixing uniformity and flow-field characteristics could be explored by $U$ from the viewpoint of experimental analysis. Furthermore, it is interesting to note that the peak value was obtained at the same experimental case $\mathrm{C}_{4}$ (see green circle and rectangle in Fig. 6 and Fig. $6 \mathrm{p}$, respectively) by all the three approaches. This indicates that uniformity measure $U$ can be an alternative route to design an optimal plating procedures. The reason is that the influence of time space and position information on mixing quality is not taken into account in the traditional assessment methods of Betti numbers. In research process, we found that the scale of structure features has significant impact on the subjective perceptive quality of mixing system. Therefore, as a pixel-based evaluation approach, the proposed technique has showed good performances for electrodeposition system.

\subsection{Characterization of the mixture homogeneity}

For investigating the characterization of the mixture homogeneity in electrolyte solution, we will now use this original method to study the influence of the operating conditions on the homogeneity degree of the blend of chloride and $\mathrm{SiO}_{2}$ particles in the aqueous solution. From the experimental analyses the following 
results are summarized:

(1) The current density of electrical field affects the mixture blend in electrolyte solution. As can be seen in Fig. 6 the mixing homogeneity becomes better with an increase of current density. For the used operating current density of $0,0.25 \mathrm{~A}$ and $1.5 \mathrm{~A}$ in our experiment, the evaluation values of the mixing uniformity of electrolyte solution under different experimental conditions were between 0.68 to 0.8 which are dimensionless. (2) The mixture homogeneity of the bath versus $s$ which indicates the distance between photographed cross section and the cathode was explored. The distance had a great effect on the solution state. (3) By analysing the effect of height on mixing uniformity, it was obtained that raising the height improves the uniformity of $\mathrm{SiO}_{2}$ particles in the bath at $t=10 \mathrm{~s}$ whereas the increase of $h$ causes deterioration of uniformity of the bath. The operating height $h$ range is $10 \mathrm{~mm}$ and $20 \mathrm{~mm}$. (4) From exploring the influence of rate on the mixing homogeneity, it was found that a rise of the stirring rate $r$ decreased the homogeneity degree in the bath from $U=0.8743$ at $r=1000 \mathrm{rpm}$ to $U=0.8178$ at $r=2000 \mathrm{rpm}$ when the images were captured at $t=10 \mathrm{~s}$. Combined with the characterization result at $t=20 \mathrm{~s}$, it appears that the uniformity measure $U$ also fell slightly which indicates that the solution mixing becomes worse.

\section{Conclusions}

In this paper, we introduce an original image analysis technique to be employed for investigating the visualization problem of electrodeposited $\mathrm{Zn}-\mathrm{Fe}-\mathrm{SiO}_{2}$ composite bath. Based on the present experimental results and considerations of the above investigation concerning the characterization of electrolyte solution of $\mathrm{Zn}-\mathrm{SiO}_{2}$ composite electrodeposition, the following conclusions can be made:

(1) In order to address the problem of flow field characterization without intrusion for composite electrodeposition, the methodology of the modified image entropy based technique for the uniformity measurement of flow field was proposed. The method shows good correspondence to computer simulated images, with known generation process, and have successfully been applied also on real images. This technique could allow a hydrodynamic characterisation of the reactor by evaluating the mixing homogeneity between micro-particles or other particles. (2) Our results confirm that the $U$ is sensitive to 
the variation of $I, s, h$ and $r$ which have strong influence on electrodeposited composite coatings. The experimental results show that the novel method can give reliable assessment and are well suited to describe flow field quantitatively. The theoretical results are in good agreement with the experimental data. Therefore, a lot of experiments need to be done to choose the optimum operating parameters by this proposed method. (3) This image analysis processing used here for mixture picture is interesting and effective. These studies thus offer a new strategy to other measuring techniques (electrical capacitance, NIR, etc.). However, a remark is concerning the shortcoming of the conclusions drawn employing $2 \mathrm{D}$ images. There is a number of growing needs to make a 2D-to-3D inference in the further work.

\section{Acknowledgements}

We gratefully acknowledge very helpful and constructive comments and suggestions made by three anonymous referees, which leads to significant improvements to the paper. This work is supported by National Natural Science Foundation of China (Nos.: 51666006 \& 51406071 , to J. Xu; 51361018, to Y. Fan), Joint Funds of the National Natural Science Foundation of China (No.: U1602272, to H. Wang), Scientific and Technological Leading Talent Projects in Yunnan Province (No.: 2015HA019, to H. Wang) and Academician Workstation of ZHANG Wenhai in Yunnan Province (No.: 2015IC005, to H. Wang). The authors express their appreciation for the help of Prof. Wuqiang Yang (The University of Manchester) and Dr. Xianming Cheng (Kunming University of Science and Technology).

\section{References}

[1] Y. Zhang, Y. Fan, X. Yang, Z. Chen, J. Zhang, The process and mechanism of electrodepositing a Zn-Fe-SiO 2 composite coating, Plating \& Surface Finishing 91 (9) (2004) 39-43.

[2] S. T. Aruna, V. K. William Grips, K. S. Rajam, Ni-based electrodeposited composite coating exhibiting improved microhardness, corrosion and wear resistance properties, Journal of Alloys \& Compounds 468 (1) (2009) 546-552.

[3] Y. Y. Fan, J. X. Xu, Y. H. Jiang, W. Q. Wang, Numerical simulation and PIV test on flow-field character of zinc-silica composite electrolyte, in: Materials Science Forum, 2011, pp. 440-445.

[4] B. Han, M. Zhang, C. Qi, N. Cui, Y. Wang, Characterization and friction-reduction performances of composite coating produced by laser cladding and ion sulfurizing, Materials Letters 150 (2015) 35-38. 
[5] V. A. Paramonov, V. V. Levenkov, Production of automobile sheet with coatings, Metallurgist 48 (9) (2004) $473-477$.

[6] V. Zúniga, R. Ortega, Y. Meas, G. Trejo, Electrodeposition of zinc from an alkaline non-cyanide bath: influence of a quaternary aliphatic polyamine, Plating \& Surface Finishing 91 (6) (2004) 46-51.

[7] C. N. Panagopoulos, K. G. Georgarakis, S. Petroutzakou, Sliding wear behaviour of zinc-cobalt alloy electrodeposits, Journal of Materials Processing Technology 160 (2) (2005) 234-244.

[8] X. Xia, I. Zhitomirsky, J. R. McDermid, Electrodeposition of zinc and composite zinc-yttria stabilized zirconia coatings, Journal of Materials Processing Technology 209 (5) (2009) 2632-2640.

[9] R. Ramanauskas, L. Muleshkova, L. Maldonado, P. Dobrovolskis, Characterization of the corrosion behaviour of Zn and Zn alloy electrodeposits: atmospheric and accelerated tests, Corrosion Science 40 (2-3) (1998) 401-410.

[10] A. Shamsolhodaei, H. Rahmani, S. Rastegari, Effects of electrodeposition parameters on morphology and properties of Zn- $\mathrm{TiO}_{2}$ composite coating, Surface Engineering 29 (9) (2013) 695-699.

[11] B. Ramezanzadeh, S. Y. Arman, M. Mehdipour, Anticorrosion properties of an epoxy zinc-rich composite coating reinforced with zinc, aluminum, and iron oxide pigments, Journal of Coatings Technology \& Research 11 (5) (2014) 727-737.

[12] Y. Y. Fan, P. Lin, S. D. Shi, Silicate-based passivation technique on alkaline electrodeposited zinc coatings, Advanced Materials Research 154-155 (2010) 433-436.

[13] T. R. Khan, A. Erbe, M. Auinger, F. Marlow, M. Rohwerder, Electrodeposition of zinc-silica composite coatings: challenges in incorporating functionalized silica particles into a zinc matrix, Science \& Technology of Advanced Materials $12(5)$ 055005 .

[14] A. P. I. Popoola, V. S. Aigbodion, O. S. I. Fayomi, Surface characterization, mechanical properties and corrosion behaviour of ternary based $\mathrm{Zn}-\mathrm{ZnO}-\mathrm{SiO}_{2}$ composite coating of mild steel, Journal of Alloys \& Compounds 654 (2016) 561-566.

[15] L. Q. Zhu, Electrodeposition of zinc-iron alloy from an alkaline zincate bath, Metal Finishing 96 (11) (1998) 54, 56-57.

[16] L. L. Barbosa, G. A. Finazzi, P. C. Tulio, I. A. Carlos, Electrodeposition of zinc-iron alloy from an alkaline bath in the presence of sorbitol, Journal of Applied Electrochemistry 38 (1) (2008) 115-125.

[17] A. G. Marques, M. G. Taryba, A. S. Panão, S. V. Lamaka, A. M. Simões, Application of scanning electrode techniques for the evaluation of ironczinc corrosion in nearly neutral chloride solutions, Corrosion Science 104 (2015) 123-131.

[18] Z. Shahri, S. R. Allahkaram, A. Zarebidaki, Electrodeposition and characterization of Co-BN (h) nanocomposite coatings, Applied Surface Science 276 (276) (2013) 174-181.

[19] F. Xia, H. Xu, C. Liu, J. Wang, J. Ding, C. Ma, Microstructures of Ni-AlN composite coatings prepared by pulse electrodeposition technology, Applied Surface Science 271 (5) (2013) 7-11.

[20] M. Yamamoto, K. Nishikawa, T. Nishiuchi, Quantitative analysis of individual atom images in FIM of an ordered $\mathrm{Ni}_{4} \mathrm{Mo}$ alloy, Applied Surface Science 87 (87) (1995) 291-297.

[21] B. J. Tyler, Multivariate statistical image processing for molecular specific imaging in organic and bio-systems, Applied Surface Science 252 (19) (2006) 6875-6882. 
[22] Q. Xiao, J. Pan, Z. Lv, J. Xu, H. Wang, Measure of bubble non-uniformity within circular region in a direct-contact heat exchanger, International Journal of Heat and Mass Transfer 110 (2017) 257-261.

[23] A. L. L. Coënt, A. Rivoire, S. Briançon, J. Lieto, An original image-processing technique for obtaining the mixing time: The box-counting with erosions method, Powder Technology 152 (1) (2005) 62-71.

[24] C. Xie, H. Zhang, L. J. Shimkets, O. A. Igoshin, Statistical image analysis reveals features affecting fates of Myxococcus xanthus developmental aggregates, Proceedings of the National Academy of Sciences of the United States of America 108 (14) (2011) 5915-5920.

[25] Q. Xiao, J. Xu, H. Wang, Quantifying the evolution of flow boiling bubbles by statistical testing and image analysis: toward a general model, Scientific Reports 6 (2016) 31548.

[26] Q. Xiao, Y. Zhai, Z. Lv, J. Xu, J. Pan, H. Wang, Non-uniformity quantification of temperature and concentration fields by statistical measure and image analysis, Applied Thermal Engineering 124 (2017) 1134-1141.

[27] M. Zaborowski, A. Barcz, M. Adamiec, Hillock recognition by digital image processing, Applied Surface Science 91 (1-4) (1995) 246-250.

[28] I. Lapsker, J. Azoulay, M. Rubnov, Z. Regev, R. C. Peled, A. Peled, Image analysis of structural changes in laser irradiated thin films of photodeposited a-Se, Applied Surface Science 106 (106) (1996) 316-320.

[29] K. Oshida, M. Murata, K. Fujiwara, T. Itaya, T. Yanagisawa, K. Kimura, T. Nakazawa, Y. A. Kim, M. Endo, B. H. Kim, Structural analysis of nano structured carbon by transmission electron microscopy and image processing, Applied Surface Science 275 (7) (2013) 409-412.

[30] Q. Xiao, J. Pan, J. Xu, H. Wang, Z. Lv, Hypothesis-testing combined with image analysis to quantify evolution of bubble swarms in a direct-contact boiling heat transfer process, Applied Thermal Engineering 113 (2016) 851-857.

[31] G. A. Gottwald, I. Melbourne, A new test for chaos in deterministic systems, Proceedings of the Royal Society A Mathematical, Physical and Engineering Sciences 460 (2042) (2004) 603-611.

[32] Q. Xiao, S. Wang, Z. Zhang, J. Xu, Analysis of sunspot time series (1749-2014) by means of 0-1 test for chaos detection, in: International Conference on Computational Intelligence and Security, 2015, pp. 215-218.

[33] J. S. A. E. Fouda, J. Y. Effa, M. Kom, M. Ali, The three-state test for chaos detection in discrete maps, Applied Soft Computing 13 (12) (2013) 4731-4737.

[34] J. S. A. E. Fouda, W. Koepf, Efficient detection of the quasi-periodic route to chaos in discrete maps by the three-state test, Nonlinear Dynamics 78 (2) (2014) 1477-1487.

[35] J. Xu, X. Sang, H. Wang, Y. Fan, An assessment of the effects of micron-particle aggregation on the performance of zinc-silica composite coatings using Betti numbers, Advances in Materials Science \& Engineering 2013 (1) (2013) 1-8.

[36] Y. Y. Fan, Y. J. Zhang, P. Dong, Preparation and property of electrodeposited $\mathrm{Zn}-\mathrm{Fe}-\mathrm{SiO}_{2}$ composite coating, Key Engineering Materials 373-374 (2008) 212-215.

[37] Y. Y. Fan, Y. J. Zhang, P. Dong, Research on zinc-silica composite plating, Advanced Materials Research 79-82 (2009) 
1903-1906.

[38] X. F. Liu, H. G. Wang, H. C. Gu, Fractal characteristic analysis of electrochemical noise with wavelet transform, Corrosion Science 48 (6) (2006) 1337-1367. 


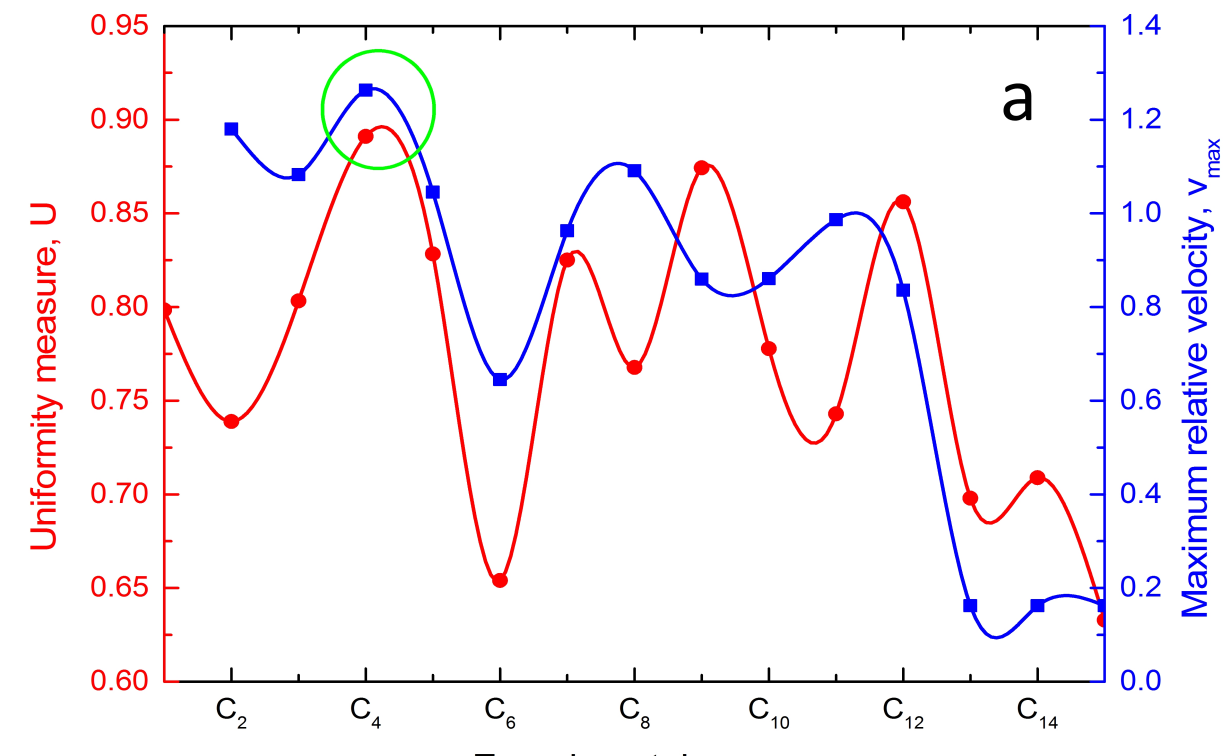

Experimental cases

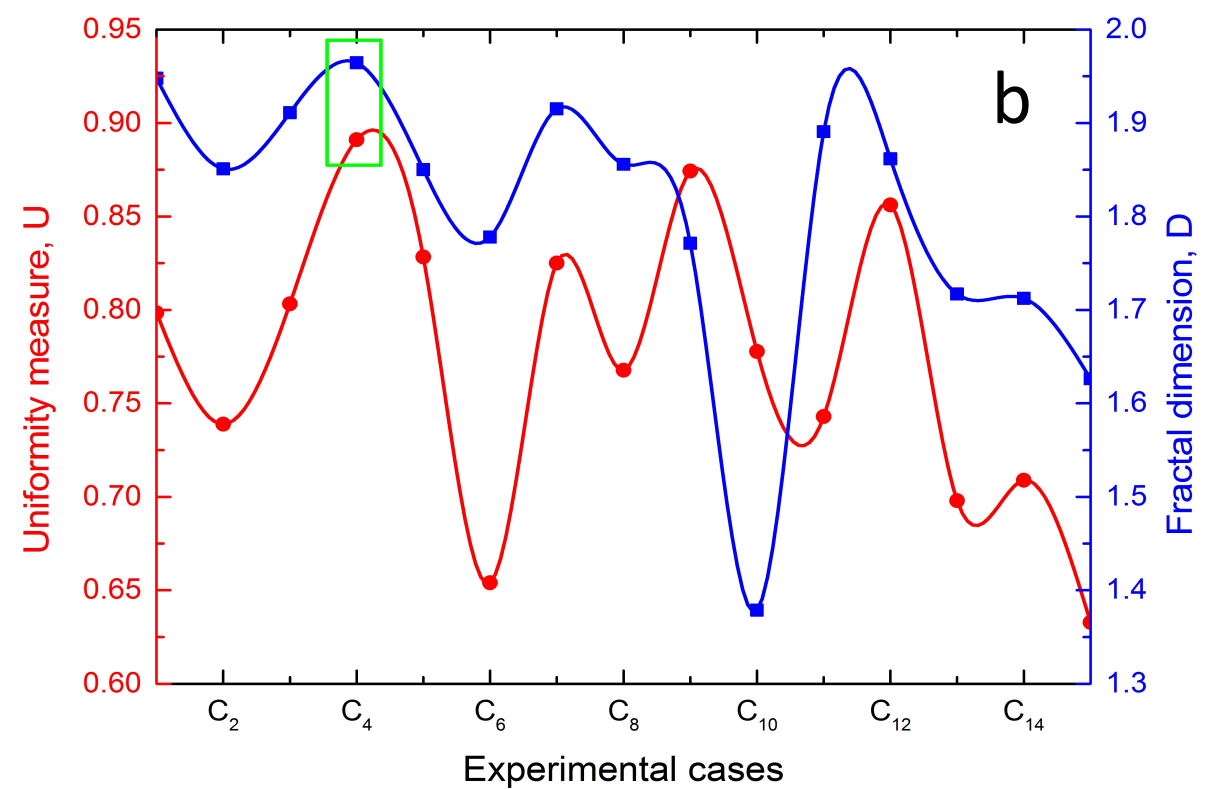

Figure 6: Comparisons of uniformity measure $U$ with maximus relative velocity $v_{\max }$ (a) and fractal dimension $D(\mathrm{~b})$. (For interpretation of the references to color in this figure legend, the reader is referred to the web version of this article.) 